\title{
Lisina digestível em dietas de baixa proteína para frangos de corte tipo caipira de um aos 28 dias
}

\author{
[Digestible lysine in diets containing low protein concentrations for broiler \\ type redneck from 1 to 28 days] \\ H.G. Oliveira ${ }^{1}$, A.S. Carrijo ${ }^{2}$, C. Kiefer ${ }^{2}$, E.R.M. Garcia ${ }^{3}$, J.A. Oliveira ${ }^{4}$, J.B. Silva ${ }^{4}$, \\ L.N. Freitas ${ }^{4}$, S.F. Horing ${ }^{4}$ \\ ${ }^{1}$ Aluna de pós-graduação - Universidade Federal de Mato Grosso do Sul - UFMS - Campo Grande, MS \\ ${ }^{2}$ Faculdade de Medicina Veterinária e Zootecnia - UFMS - Campo Grande, MS \\ ${ }^{3}$ Universidade Estadual de Mato Grosso do Sul - UEMS - Aquidauana, MS \\ ${ }^{4}$ Aluno de graduação - UFMS - Campo Grande, MS
}

\begin{abstract}
RESUMO
Avaliou-se a inclusão de diferentes porcentagens de lisina digestível em dietas de baixa proteína para frangos de corte tipo caipira, machos e fêmeas, com idade entre um e 28 dias. Utilizaram-se 792 machos e 792 fêmeas de linhagem comercial, de um dia de idade, distribuídos em delineamento inteiramente ao acaso, em esquema fatorial $2 \times 6$ (sexo x porcentagem de lisina digestível: 0,$85 ; 0,90 ; 0,95 ; 1,00 ; 1,05$ e $1,10 \%)$ com seis repetições de 22 aves. Não foi constatada interação $(\mathrm{P}>0,05)$ de sexo versus inclusão de lisina. Observou-se superioridade $(\mathrm{P}<0,05)$ dos machos em relação às fêmeas para todas as variáveis avaliadas. $\mathrm{O}$ ganho de peso dos frangos diminuiu linearmente $(\mathrm{P}<0,05)$ em função do aumento da porcentagem de lisina digestível na dieta e observou-se redução linear $(\mathrm{P}<0,01)$ nos consumos de ração e de proteína. $\mathrm{O}$ consumo de lisina digestível aumentou linearmente $(\mathrm{P}<0,01)$ em função do aumento de sua concentração na dieta. Não houve diferença $(\mathrm{P}>0,05)$ para conversão alimentar. Da composição centesimal da carcaça, apenas o percentual de matéria mineral foi influenciada $(\mathrm{P}<0,05)$ pela porcentagem de lisina digestível. Conclui-se que $0,85 \%$ de lisina para frangos tipo caipira de pescoço pelado atende à exigência nutricional de lisina digestível em dietas com baixa concentração proteica.
\end{abstract}

Palavras-chave: aminoácidos, carcaça, desempenho, frango, sistema semi-intensivo

\begin{abstract}
The inclusion of different percentages of digestible lysine in low-protein diets was evaluated for male and female free-range broiler chickens, from 1 to 28 days. We used 792 female and 792 male naked neck chickens a day in a completely randomized $2 x 6$ factorial scheme (sex x percentages of digestible lysine: 0.85, 0.90, 0.95, 1.00, 1.05 and 1.10\%) with six replicates of 22 broilers. No interaction of sex versus lysine was found. Superiority was observed $(P<0.05)$ in males compared to females for all variables. Weight gain of chickens decreased linearly $(P<0.05)$ with increasing levels of digestible lysine in the diet. There was a linear reduction $(P<0.01)$ in feed intake, protein and metabolizable energy. On the other hand, the consumption of digestible lysine increased linearly $(P<0.01)$ with the increase of its concentration in the diet. There was no difference $(P>0.05)$ in food conversion. In the chemical composition of the carcass, only the percentage of mineral matter was influenced $(P<0.05)$ by digestible lysine levels. It was concluded that the level of $0.85 \%$ for type redneck broiler meets the nutritional requirement of digestible lysine in diets containing lower protein concentrations.
\end{abstract}

Keywords: amino acids, broiler, carcass, performance, semi-intensive system

Recebido em 22 de outubro de 2011

Aceito em 12 de dezembro de 2012

*Autor para correspondência (corresponding author)

E-mail: charles.kiefer@ufms.br 


\section{INTRODUÇÃO}

A criação de frangos de corte tipo caipira no sistema semi-intensivo tem sido uma alternativa para satisfazer novas tendências de consumo. O novo contexto de qualidade inclui o sistema de produção, que promove o bem-estar animal, preserva o meio ambiente, reduz promotores de crescimento e antibióticos. A carne produzida possui um sabor diferenciado, que agrada ao paladar de consumidores à procura de alimentos com maiores atributos de qualidade (Carrijo et al., 2010).

Considerando que a alimentação representa cerca de $70 \%$ dos custos de produção, medidas para reduzir esses custos podem significar lucro para o setor. Os custos com a alimentação das aves estão associados ao atendimento das exigências de aminoácidos, posto que, nas dietas formuladas, utilizam-se basicamente milho e farelo de soja como fontes de energia e proteína, respectivamente. Essa combinação de ingredientes resulta em dietas limitantes em metionina e lisina, sendo necessária a suplementação por meio de aminoácidos industriais, a fim de que as aves tenham suas exigências nutricionais atendidas e expressem o seu potencial genético.

A lisina é o nutriente diretamente envolvido no desenvolvimento das aves, pois se trata de um aminoácido essencial cujo principal papel fisiológico consiste na síntese de proteínas musculares (Costa et al., 2001; Lana et al., 2005). Dietas deficientes em lisina podem ter efeitos diretos sobre o desenvolvimento muscular, influenciando o desempenho, as características de carcaça e a composição corporal das aves.

Muitos estudos têm sido realizados para avaliar as exigências de aminoácidos para frangos de corte, uma vez que esses nutrientes participam da síntese de proteínas musculares, influenciando diretamente o desempenho das aves. Contudo, faltam estudos para determinar as exigências de aminoácidos de frangos de corte do tipo caipira. Portanto, realizou-se este estudo com o objetivo de avaliar porcentagem de inclusão de lisina digestível em dietas de baixa proteína para frangos de corte tipo caipira, machos e fêmeas, com idade entre um e 28 dias.

\section{MATERIAL E MÉTODOS}

Foram utilizadas 792 fêmeas e 792 machos de corte da linhagem Label Rouge Sasso, de um dia de idade. $\mathrm{O}$ delineamento experimental utilizado foi o inteiramente ao acaso, em esquema fatorial 2x6 (dois sexos e seis porcentagens de lisina digestível: 0,$85 ; 0,90 ; 0,95 ; 1,00 ; 1,05$ e $1,10 \%$ ) com seis repetições, sendo cada unidade experimental composta por 22 aves.

Foi utilizada uma dieta basal composta por sorgo de baixo tanino e farelo de soja, a qual continha $2.900 \mathrm{kcal}$ de energia metabolizável $/ \mathrm{kg}$ de ração, $15 \%$ de proteína bruta e $0,85 \%$ de lisina digestível, suplementada com minerais, vitaminas e aminoácidos, de modo a atender as exigências nutricionais conforme recomendações de Rostagno et al. (2005) para aves de reposição semipesadas de uma a seis semanas de idade, exceto para o nível de lisina digestível e proteína (Tab. 1). As demais dietas foram elaboradas a partir da inclusão de L-lisina $\mathrm{HCl}$ (99\%), contendo $79,2 \%$ de lisina e considerando-a com $100 \%$ de digestibilidade verdadeira, em substituição ao amido de milho. As aves receberam ração e água à vontade.

As aves foram alojadas em box equipado com campânula contendo duas lâmpadas incandescentes de $100 \mathrm{~W}$, um comedouro tubular e um bebedouro pendular. A cama utilizada foi de maravalha, com oito centímetros de espessura. As aves permaneceram confinadas até os 28 dias de idade. O programa de luz adotado foi o de iluminação artificial de 24 horas nos primeiros sete dias e de luz natural até o final do período experimental. Durante o período experimental, as temperaturas mínima e máxima registradas foram de $21,9 \pm 4,0$ e $31,7 \pm 3,5$, respectivamente. As umidades relativas do ar mínima e máxima foram de 46,7 $\pm 12,4$ e $74,7 \pm 10,3$, respectivamente. A ocorrência de mortalidade também foi registrada diariamente. 
Lisina digestível em dietas...

Tabela 1. Composições centesimal e nutricional calculada das dietas experimentais

\begin{tabular}{|c|c|c|c|c|c|c|}
\hline \multirow{2}{*}{ Ingrediente } & \multicolumn{6}{|c|}{ Lisina digestível (\%) } \\
\hline & 0,85 & 0,90 & 0,95 & 1,00 & 1,05 & 1,10 \\
\hline Farelo de soja (45\%) & 15,480 & 15,480 & 15,480 & 15,480 & 15,480 & 15,480 \\
\hline Sorgo (baixo tanino) & 79,093 & 79,093 & 79,093 & 79,093 & 79,093 & 79,093 \\
\hline Fosfato bicálcico & 1,789 & 1,789 & 1,789 & 1,789 & 1,789 & 1,789 \\
\hline Calcário & 1,148 & 1,148 & 1,148 & 1,148 & 1,148 & 1,148 \\
\hline L-lisina $\mathrm{HCl}$ & 0,407 & 0,470 & 0,533 & 0,596 & 0,659 & 0,722 \\
\hline DL-metionina & 0,348 & 0,348 & 0,348 & 0,348 & 0,348 & 0,348 \\
\hline L-treonina & 0,127 & 0,127 & 0,127 & 0,127 & 0,127 & 0,127 \\
\hline Mistura mineral ${ }^{1}$ & 0,100 & 0,100 & 0,100 & 0,100 & 0,100 & 0,100 \\
\hline Mistura vitamínica² & 0,100 & 0,100 & 0,100 & 0,100 & 0,100 & 0,100 \\
\hline Sal comum & 0,408 & 0,408 & 0,408 & 0,408 & 0,408 & 0,408 \\
\hline Amido & 0,100 & 0,937 & 0,874 & 0,811 & 0,748 & 0,685 \\
\hline TOTAL & 100,00 & 100,00 & 100,00 & 100,00 & 100,00 & 100,00 \\
\hline \multicolumn{7}{|l|}{ Composição calculada $^{3}$} \\
\hline EM aparente $(\mathrm{kcal} / \mathrm{kg})$ & 2.900 & 2.900 & 2.900 & 2.900 & 2.900 & 2.900 \\
\hline Proteína bruta (\%) & 15,00 & 15,00 & 15,00 & 15,00 & 15,00 & 15,00 \\
\hline Lisina digestível (\%) & 0,850 & 0,900 & 0,950 & 1,00 & 1,05 & 1,10 \\
\hline Met+cist digestível (\%) & 0,620 & 0,620 & 0,620 & 0,620 & 0,620 & 0,620 \\
\hline Treonina digestível (\%) & 0,570 & 0,570 & 0,570 & 0,570 & 0,570 & 0,570 \\
\hline Triptofano digestível (\%) & 0,150 & 0,150 & 0,150 & 0,150 & 0,150 & 0,150 \\
\hline Arginina (\%) & 0,979 & 0,979 & 0,979 & 0,979 & 0,979 & 0,979 \\
\hline Isoleucina (\%) & 0,566 & 0,566 & 0,566 & 0,566 & 0,566 & 0,566 \\
\hline Valina (\%) & 0,647 & 0,647 & 0,647 & 0,647 & 0,647 & 0,647 \\
\hline Cálcio & 0,940 & 0,940 & 0,940 & 0,940 & 0,940 & 0,940 \\
\hline Fósforo disponível (\%) & 0,430 & 0,430 & 0,430 & 0,430 & 0,430 & 0,430 \\
\hline Sódio $(\%)$ & 0,180 & 0,180 & 0,180 & 0,180 & 0,180 & 0,180 \\
\hline
\end{tabular}

${ }^{\mathrm{I}}$ Conteúdo por $\mathrm{kg}$ de produto: ferro, $5.000 \mathrm{mg}$; cobre, $70.000 \mathrm{mg}$; cobalto, 0,2g; manganês, 60.000mg; zinco, $50.000 \mathrm{mg}$; iodo, $1.250 \mathrm{mg}$; selênio, $200 \mathrm{mg}$ e excipiente q.s.p., $1000 \mathrm{~g}$.

${ }^{2}$ Níveis por kg de produto: vit. A, 1.500.000UI; vit. D3, 500.000UI; vit. E, 3.000UI; vit. B1, 250mg; vit. B2, $1.125 \mathrm{mg}$; vit. B6, 375mg; ácido pantotênico, 10g; vit. K3, 200g; ácido nicotínico,7.500mg; vit. B12, 3.0000mg; ácido fólico, $1.375,5 \mathrm{mg}$; biotina, $12,5 \mathrm{mg}$; colina, $81.250 \mathrm{mg}$ e excipiente q.s.p., $1000 \mathrm{~g}$.

${ }^{3}$ Composição nutricional estimada segundo informações contidas em Rostagno et al. (2005).

EM: energia metabolizável.

As variáveis analisadas foram os consumos de ração, proteína bruta e lisina digestível $(\mathrm{g})$, ganho de peso $(\mathrm{g})$, conversão alimentar e composição química da carcaça. O ganho de peso e a conversão alimentar foram corrigidos pela mortalidade segundo Sakomura e Rostagno (2007). O peso final foi o peso absoluto médio das aves aos 28 dias. $\mathrm{O}$ ganho de peso foi obtido pela diferença entre os pesos final e inicial. $\mathrm{O}$ consumo de ração foi determinado subtraindo-se as sobras da quantidade de ração fornecida, sendo o resultado dividido pelo número de aves do box. A conversão alimentar foi estabelecida pela relação entre o consumo de ração e o ganho de peso.

Ao final do período experimental, após seis horas de jejum de sólidos, foram abatidas três aves de cada repetição, com o peso mais próximo da média $( \pm 5 \%)$. As aves foram insensibilizadas por deslocamento cervical e sangria, procedimentos aprovados pela Comissão de Ética no Uso de animais/CEUA/UFMS, sob o protocolo $n^{\circ}$ 230/2009. As carcaças inteiras das aves abatidas (incluindo cabeça e pés), sem as vísceras e o sangue, foram trituradas individualmente e homogeneizadas. Após, retirou-se uma amostra de $60 \mathrm{~g}$ para realização das análises bromatológicas (matéria seca, umidade, matéria mineral e proteína bruta) de acordo com as metodologias descritas por Silva e Queiroz (2002).

Os resultados foram submetidos às análises de variância e de regressão, com auxílio do programa estatístico SAS 9.0 (2002) e a 5\% de probabilidade. 


\section{RESULTADOS E DISCUSSÃO}

Não foi constatada interação $(\mathrm{P}>0,05)$ do sexo das aves versus porcentagem de lisina digestível para as características de desempenho (Tab. 2). Observou-se efeito $(\mathrm{P}<0,01)$ de sexo para todas as variáveis de desempenho, em que os machos apresentaram maiores peso final, consumos de ração, de lisina e de proteína, ganho de peso e conversão alimentar quando comparados às fêmeas. Estes resultados estão de acordo com as informações encontradas na literatura, em que se verifica consistentemente superioridade dos machos em relação às fêmeas tanto em frangos de corte em sistema tradicional (Sabino et al., 2004; Kolling et al., 2005; Carvalho et al., 2009) quanto em aves de corte de crescimento lento (Nagib Nascimento et al., 2009).

Tabela 2. Desempenho de frangos de corte tipo caipira, machos e fêmeas, submetidos a diferentes porcentagens de lisina digestível

\begin{tabular}{|c|c|c|c|c|c|c|c|c|c|c|c|c|}
\hline \multirow{2}{*}{ Variável } & \multirow{2}{*}{ Sexo } & \multicolumn{6}{|c|}{ Lisina digestível (\%) } & \multirow{2}{*}{ Média } & \multirow{2}{*}{$\begin{array}{c}\mathrm{CV}, \\
\%\end{array}$} & \multicolumn{3}{|c|}{$<\mathrm{P}$} \\
\hline & & 0,85 & 0,90 & 0,95 & 1,00 & 1,05 & 1,10 & & & Sexo & Porc. & Sexo*Porc. \\
\hline \multirow{3}{*}{$\begin{array}{l}\text { Peso final, } \\
\qquad \mathrm{g}^{1}\end{array}$} & Macho & 510,67 & 494,45 & 510,51 & 475,95 & 485,30 & 472,13 & $491,50 \mathrm{a}$ & & & & \\
\hline & Fêmea & 456,47 & 441,31 & 446,70 & 431,63 & 407,83 & 410,32 & $432,38 b$ & 4,99 & $<0,01$ & $<0,01$ & 0,61 \\
\hline & Média & 483,57 & 467,88 & 478,61 & 453,79 & 446,56 & 441,22 & & & & & \\
\hline \multirow{3}{*}{$\begin{array}{l}\text { Consumo } \\
\text { de ração, } \\
\mathrm{g}^{1}\end{array}$} & Macho & 1067 & 999 & 1019 & 978 & 969 & 981 & $1002 \mathrm{a}$ & & & & \\
\hline & Fêmea & 1007 & 936 & 979 & 945 & 912 & 914 & $949 b$ & 5,32 & $<0,01$ & $<0,01$ & 0,95 \\
\hline & Média & 1037 & 967 & 999 & 962 & 940 & 948 & & & & & \\
\hline \multirow{3}{*}{$\begin{array}{l}\text { Consumo } \\
\text { de lisina, } \\
\mathrm{g}^{1}\end{array}$} & Macho & 8,91 & 8,99 & 9,68 & 9,78 & 10,17 & 10,80 & 9,72 & & & & \\
\hline & Fêmea & 8,56 & 8,43 & 9,29 & 9,45 & 9,57 & 10,05 & 9,23 & 6,20 & $<0,01$ & $<0,01$ & 0,94 \\
\hline & Média & 8,74 & 8,71 & 9,49 & 9,62 & 9,87 & 10,42 & & & & & \\
\hline \multirow{3}{*}{$\begin{array}{l}\text { Consumo } \\
\text { de proteína } \\
\text { bruta, } \mathrm{g}^{1}\end{array}$} & Macho & 160,07 & 149,81 & 152,82 & 146,69 & 145,36 & 147,24 & $150,33 \mathrm{a}$ & & & & \\
\hline & Fêmea & 151,10 & 140,45 & 146,80 & 141,82 & 136,75 & 137,05 & $142,33 b$ & 5,32 & $<0,01$ & $<0,01$ & 0,95 \\
\hline & Média & 155,59 & 145,13 & 149,81 & 144,26 & 141,06 & 142,15 & & & & & \\
\hline \multirow{3}{*}{$\begin{array}{l}\text { Ganho de } \\
\text { peso, } \mathrm{g}^{1}\end{array}$} & Macho & 472,78 & 456,30 & 472,51 & 437,77 & 447,31 & 433,86 & $453,42 \mathrm{a}$ & & & & \\
\hline & Fêmea & 420,75 & 405,62 & 410,82 & 395,79 & 371,87 & 374,37 & $396,54 b$ & 5,45 & $<0,01$ & $<0,01$ & 0,60 \\
\hline & Média & 446,77 & 430,96 & 441,66 & 416,78 & 409,59 & 404,12 & & & & & \\
\hline \multirow{3}{*}{$\begin{array}{l}\text { Conversão } \\
\text { alimentar }\end{array}$} & Macho & 2,30 & 2,30 & 2,24 & 2,26 & 2,30 & 2,32 & $2,29 \mathrm{~b}$ & & & & \\
\hline & Fêmea & 2,49 & 2,37 & 2,44 & 2,45 & 2,42 & 2,48 & $2,44 \mathrm{a}$ & 5,34 & $<0,01$ & 0,77 & 0,79 \\
\hline & Média & 2,40 & 2,34 & 2,34 & 2,36 & 2,36 & 2,40 & & & & & \\
\hline
\end{tabular}

Médias seguidas de letras diferentes na mesma coluna diferem entre si pelo teste de $\mathrm{SNK}(\mathrm{P}<0,05)$.

${ }^{1}$ Efeito linear $(\mathrm{P}<0,001)$.

Constatou-se que o aumento da porcentagem de lisina digestível reduziu linearmente $(\mathrm{P}<0,01)$ o peso final das aves. Da mesma forma, observou-se que o aumento da concentração de lisina digestível na dieta reduziu linearmente $(\mathrm{P}<0,01)$ os consumos de ração e de proteína, enquanto o consumo de lisina digestível aumentou linearmente $(\mathrm{P}<0,01)$ em função do aumento de sua concentração na dieta.

Os resultados diferem dos observados por Lana et al. (2005) e Nagib Nascimento et al. (2009), que, ao avaliarem porcentagens de 1,04 a
$1,22 \%$ e 0,85 a $1,21 \%$ de lisina digestível, respectivamente, observaram aumento do ganho de peso e do peso final das aves em razão da suplementação de lisina digestível na dieta, mantendo constante a relação dos aminoácidos no padrão de proteína ideal.

Alimentos com desequilíbrio de aminoácidos podem induzir ao decréscimo acentuado do consumo, e rações com baixo nível proteico tendem a apresentar baixa intensidade de metabolização de nitrogênio, o que pode resultar em menor habilidade de catabolisar a fonte 
desbalanceada em aminoácidos. Assim, mesmo que a dieta apresente desbalanço de aminoácidos não muito severo, a porcentagem proteica baixa induz ao menor consumo desse alimento (Macari et al., 2002).

A depressão na ingestão de alimento de acordo com o aumento da concentração de lisina digestível na dieta observada neste estudo pode estar relacionada com o imbalanço aminoacídico, uma vez que não se manteve constante o padrão de proteína ideal entre as dietas experimentais. O imbalanço de aminoácidos é caracterizado em situações em que pelo menos um aminoácido está abaixo da exigência, o qual é denominado aminoácido limitante (Leeson e Summers, 2001). Além disso, dietas com baixa porcentagem proteica e excesso de pelo menos um aminoácido podem resultar no acúmulo desse nutriente nos fluidos corporais e diminuir o consumo de ração, caracterizando o imbalanço aminoacídico (Sklan e Plavnik, 2002).

Os aminoácidos livres provenientes das dietas suplementadas com aminoácidos sintéticos aparecem em menores concentrações no sangue portal do que os provenientes da proteína intacta (Bregendahl et al., 2002). Os peptídeos derivados da digestão da proteína intacta são absorvidos de maneira mais rápida pelos enterócitos do que os aminoácidos livres presentes em dietas suplementadas com aminoácidos sintéticos (Rutz, 2002). Essa menor taxa de absorção resulta em menor disponibilidade de aminoácidos essenciais para síntese proteica (Pinchasov et al., 1990), influenciando o ganho de peso, conforme constatado no presente trabalho. De acordo com essa hipótese, o mínimo de proteína intacta deve ser fornecido para que o desempenho das aves não seja prejudicado.

Outra hipótese para a redução do consumo em função do aumento da concentração de lisina observada neste estudo pode estar relacionada com o antagonismo aminoacídico. $\mathrm{O}$ antagonismo é considerado como o efeito do aumento da concentração específica de um aminoácido acima da exigência interferindo na utilização metabólica de outro aminoácido. Especificamente as concentrações elevadas de lisina na dieta podem resultar na competição com a arginina pelos sítios de transporte ativos dos enterócitos, prejudicar a reabsorção de arginina nos rins e estimular a produção de arginase renal, o que leva à formação de ornitina e ureia a partir da arginina (Leeson e Summers, 2001).

A redução do ganho de peso e, consequentemente, do peso final das aves alimentadas com as dietas contendo maiores concentrações de lisina está diretamente relacionada à redução dos consumos de ração e de proteína. Como houve redução do consumo de ração e do ganho de peso em razão do aumento da concentração de lisina na dieta, a conversão alimentar não foi influenciada $(\mathrm{P}>0,05)$ pelos tratamentos.

Apesar de a magnitude das respostas ter variado entre os sexos para todas as variáveis analisadas, a ausência de interação $(\mathrm{P}>0,05)$ entre sexo e porcentagem de lisina indica que $o$ comportamento das respostas de machos $\mathrm{e}$ fêmeas para as variáveis foi semelhante, justificando o ajuste de apenas uma equação para ambos os sexos (Tab. 3).

Tabela 3. Equações de regressão para as variáveis de desempenho em função da porcentagem de lisina digestível

\begin{tabular}{ccc}
\hline Modelo & Variável/Equação & $\mathrm{R}^{2}$ \\
\hline Linear & Peso $(\mathrm{g})$ & 0,85 \\
Linear & Peso $=629,38-171,73 \mathrm{Lis}$ & 0,85 \\
& Ganho de peso $(\mathrm{g})$ & 0,68 \\
Linear & Ganho $=593,37-172,71 \mathrm{Lis}$ & 0,94 \\
& Consumo de ração $(\mathrm{g})$ & 0,69 \\
Linear & Consumo $=1289,2-321,71 \mathrm{Lis}$ & 0,69 \\
& Consumo de lisina $(\mathrm{g})$ & \\
\hline
\end{tabular}


De acordo com os resultados de desempenho obtidos e as equações de regressão estabelecidas, pode-se inferir que $0,85 \%$ atende à exigência de lisina digestível para frangos de corte tipo caipira de crescimento lento, do primeiro aos 28 dias de idade, alimentados com dietas contendo baixa concentração de proteína.
Não foi constatada interação $(\mathrm{P}>0,05)$ de sexo versus porcentagem de lisina digestível para a composição de carcaça (Tab. 4). Observou-se efeito isolado $(\mathrm{P}<0,01)$ de sexo sobre a composição de carcaça das aves, de forma que os machos apresentaram menor conteúdo de matéria seca e de proteína bruta e maior conteúdo de umidade e matéria mineral na carcaça quando comparados às fêmeas.

Tabela 4. Composição química da carcaça de frangos tipo caipira, machos e fêmeas, submetidos a diferentes porcentagens de lisina digestível

\begin{tabular}{|c|c|c|c|c|c|c|c|c|}
\hline \multirow{2}{*}{ Variável } & \multirow{2}{*}{ Porc. } & \multicolumn{2}{|c|}{ Sexo } & \multirow{2}{*}{ Média } & \multirow{2}{*}{$\begin{array}{c}\mathrm{CV} \\
\%\end{array}$} & \multicolumn{3}{|c|}{$\mathrm{P}<$} \\
\hline & & Macho & Fêmea & & & Sexo & Porc. & Sexo*Porc. \\
\hline \multirow{7}{*}{$\begin{array}{l}\text { Matéria } \\
\text { seca, \% }\end{array}$} & 0,85 & 33,21 & 34,71 & 33,96 & \multirow{7}{*}{4,88} & \multirow{7}{*}{$<0,01$} & \multirow{7}{*}{0,23} & \multirow{7}{*}{0,26} \\
\hline & 0,90 & 32,55 & 33,75 & 33,15 & & & & \\
\hline & 0,95 & 32,95 & 34,32 & 33,64 & & & & \\
\hline & 1,00 & 32,98 & 33,78 & 33,38 & & & & \\
\hline & 1,05 & 33,83 & 33,61 & 33,72 & & & & \\
\hline & 1,10 & 33,41 & 34,50 & 33,95 & & & & \\
\hline & Média & $33,16 b$ & $34,11 \mathrm{a}$ & & & & & \\
\hline \multirow{7}{*}{$\begin{array}{c}\text { Umidade, } \\
\%\end{array}$} & 0,85 & 66,79 & 65,29 & 66,04 & \multirow{7}{*}{2,47} & \multirow{7}{*}{$<0,01$} & \multirow{7}{*}{0,23} & \multirow{7}{*}{0,26} \\
\hline & 0,90 & 67,44 & 66,25 & 66,85 & & & & \\
\hline & 0,95 & 67,04 & 65,68 & 66,36 & & & & \\
\hline & 1,00 & 67,02 & 66,21 & 66,62 & & & & \\
\hline & 1,05 & 66,17 & 66,39 & 66,28 & & & & \\
\hline & 1,10 & 66,59 & 65,49 & 66,04 & & & & \\
\hline & Média & $66,84 a$ & $65,82 \mathrm{~b}$ & & & & & \\
\hline \multirow{7}{*}{$\begin{array}{c}\text { Matéria } \\
\text { mineral, \% }\end{array}$} & 0,85 & 7,48 & 7,05 & 7,27 & \multirow{7}{*}{11,04} & \multirow{7}{*}{$<0,01$} & \multirow{7}{*}{0,04} & \multirow{7}{*}{0,99} \\
\hline & 0,90 & 7,88 & 7,37 & 7,62 & & & & \\
\hline & 0,95 & 7,83 & 7,43 & 7,63 & & & & \\
\hline & 1,00 & 8,11 & 7,53 & 7,82 & & & & \\
\hline & 1,05 & 8,10 & 7,52 & 7,81 & & & & \\
\hline & 1,10 & 7,62 & 7,24 & 7,43 & & & & \\
\hline & Média & $7,84 \mathrm{a}$ & $7,36 \mathrm{~b}$ & & & & & \\
\hline \multirow{7}{*}{$\begin{array}{l}\text { Proteína } \\
\text { bruta, \% }\end{array}$} & 0,85 & 47,18 & 47,90 & 47,54 & \multirow{7}{*}{4,83} & \multirow{7}{*}{0,01} & \multirow{7}{*}{0,69} & \multirow{7}{*}{0,77} \\
\hline & 0,90 & 48,02 & 48,42 & 48,22 & & & & \\
\hline & 0,95 & 46,70 & 48,02 & 47,36 & & & & \\
\hline & 1,00 & 47,13 & 48,15 & 47,64 & & & & \\
\hline & 1,05 & 47,53 & 47,50 & 47,52 & & & & \\
\hline & 1,10 & 46,87 & 48,22 & 47,54 & & & & \\
\hline & Média & $47,24 \mathrm{~b}$ & $48,04 a$ & & & & & \\
\hline
\end{tabular}

Médias seguidas de letras diferentes na mesma coluna diferem entre si pelo teste de $\mathrm{SNK}(\mathrm{P}<0,05)$.

${ }^{1}$ Efeito quadrático $(\mathrm{P}<0,05): \mathrm{Y}=-18,406+52,845 \mathrm{x}-26,643 \mathrm{x}^{2}\left(\mathrm{R}^{2}=0,87\right)$.

Verificou-se efeito $(\mathrm{P}<0,05)$ da porcentagem de lisina digestível sobre o conteúdo de matéria mineral da carcaça, em que essa variável aumentou de forma quadrática até $0,99 \%$ de lisina digestível na dieta. Por outro lado, os conteúdos de matéria seca, umidade e proteína bruta da carcaça não foram influenciados $(\mathrm{P}>0,05)$ pela porcentagem de lisina digestível das dietas experimentais. Respostas similares às verificadas no presente estudo foram constatadas por outros pesquisadores (Toledo et al., 2007; Cella et al., 2009; Takeara et al., 2010), que também não constataram influência da porcentagem de lisina digestível sobre a composição química da carcaça de frangos de corte. Trindade Neto et al. (2011) observaram 
que o aumento da concentração de lisina na dieta proporcionou aumento quadrático da deposição de água na carcaça dos frangos de corte e, concomitantemente, aumento da taxa de deposição de proteína, o que é um indicativo da melhora da eficiência de utilização dos nutrientes da dieta.

Os resultados observados para composição de carcaça no presente estudo estão coerentes com a observação obtida para a conversão alimentar, em que o aumento do nível de lisina não alterou a eficiência de utilização da fração proteica da dieta e, portanto, a capacidade da ave em depositar proteína na carcaça. Fato que, provavelmente, pode ser justificado pela baixa capacidade das aves do tipo caipira em depositar proteína na carcaça em relação ao frango de corte tradicional (Fanatico et al., 2008; Madeira et al., 2010) e também pelo imbalanço aminoacídico observado nas dietas contendo maior concentração de lisina.

\section{CONCLUSÕES}

A inclusão de $0,85 \%$ atende à exigência de lisina digestível para frangos de corte tipo caipira de crescimento lento, machos e fêmeas, do primeiro aos 28 dias de idade, alimentados com dietas contendo baixa concentração proteica.

\section{REFERÊNCIAS}

BREGENDAHL, K.; SELL, J.L.; ZIMMERMAN, D.R. Effect of low-protein diets on growth performance and body composition of broiler chicks. Poult. Sci., v.81, p.1156- 1167, 2002.

CARRIJO, A.S.; FASCINA, V.B.; SOUZA, K.M.R. et $a l$. Níveis de farelo da raiz integral de mandioca em dietas para fêmeas de frangos caipiras. Rev. Bras. Saúde Prod. Anim., v.11, p.131-139, 2010.

CARVALHO, J.C.C.; BERTECHINI, A.G.; FASSANI, E.J. et al. Desempenho e características de carcaça de frangos de corte alimentados com dietas à base de milho e farelo de soja suplementadas com complexos enzimáticos. Rev. Bras. Zootec., v.38, p.292-298, 2009.

CELLA, P.S.; MURAKAMI, A.E.; FRANCO, J.R.G. et al. Níveis de lisina digestível em dietas baseadas no conceito de proteína ideal para frangos de corte na fase inicial. Cienc. Anim. Bras., v.10, p.101-106, 2009.
COSTA, F.G.P.; ROSTAGNO, H.S.; ALBINO, L.F.T. et al. Níveis dietéticos de proteína bruta para frangos de corte de 1 a 21 e 22 a 42 dias de idade. Rev. Bras. Zootec., v.30, p.1498-1505, 2001.

FANATICO, A.C.; PILLAI, P.B.; HESTER, P.Y. et al. Performance, livability, and carcass yield of slow- and fast- growing chicken genotypes fed lownutrient or standard diets and raised indoors or with outdoor access. Poult. Sci., v.87, p.1012-1021, 2008.

KOLLING, A.V.; KESSLER, A.M.; RIBEIRO, A.M.L. Desempenho e composição corporal de frangos de corte alimentados com diferentes níveis de proteína e de aminoácidos ou com livre escolha das dietas. Rev. Bras. Zootec., v.34, p.98-103, 2005.

LANA, S.R.V.; OLIVEIRA, R.F.M.; DONZELE, J.L. et al. Níveis de lisina digestível em rações para frangos de corte de 1 a 21 dias de idade mantidos em ambiente de termoneutralidade. Rev. Bras. Zootec., v.34, p.1614-1623, 2005.

LEESON, S.; SUMMERS, J.D. Nutrition of the chickens. 4.ed. Ontario: University Books, 2001. 591p.

MACARI, M.; FURLAN, R.L.; GONZALES, E. Fisiologia aviária aplicada a frangos de corte. 2.ed. Jaboticabal: FUNEP/UNESP, 2002. 375p.

MADEIRA, L.A.; SARTORI, J.R.; ARAUJO, P.C. et al. Avaliação do desempenho e do rendimento de carcaça de quatro linhagens de frangos de corte em dois sistemas de criação. Rev. Bras. Zootec., v.39, p.2214-2221, 2010

NAGIB NASCIMENTO, D.C.; SAKOMURA, N.K.; SIQUEIRA, J.C. et al. Exigências de lisina digestível para aves de corte da linhagem ISA Label criadas em semiconfinamento. Arq. Bras. Med. Vet. Zootec., v.61, p.1128-1138, 2009.

PINCHASOV, Y.; MENDONÇA, C.X.; JENSEN, L.S. et al. Broiler chick response to low protein diets supplemented with synthetic amino acids. Poult. Sci., v.69, p.1950-1955, 1990

ROSTAGNO, H.S.; ALBINO, L.F.T.; DONZELE, J.L. et al. Tabelas brasileiras para aves e suínos: composição de alimentos e exigências nutricionais. 2.ed. Viçosa: Editora UFV, 2005. 186p.

RUTZ, F. Proteínas: digestão e absorção. In: MACARI, M.; FURLAN, R.L.; GONZALES, E. (ed.). Fisiologia aviária aplicada a frangos de corte. 2.ed. Jaboticabal: FUNEP/UNESP, 2002. p.135-141.

SABINO, H.F.N.; SAKOMURA, S.K.; NEME, R. et $a l$. Níveis proteicos na ração de frangos de corte na fase de crescimento. Pesq. Agrop. Bras., v.39, p.407412, 2004. 
SAKOMURA, N.K.; ROSTAGNO, H.S. Métodos para avaliação biológica dos alimentos e exigências nutricionais para animais monogástricos. Jaboticabal: UNESP, 2007. 283p.

SILVA, D.J.; QUEIROZ, A.C. Análise de alimentos: métodos químicos e biológicos. 3.ed. Viçosa: UFV, 2002. 235p

SKLAN, D.; PLAVNIK, I. Interactions between dietary crude protein and essential amino acid intake on performance in broilers. Br. Poult. Sci., v.43, p.442-449, 2002

STATISTICAL Analysis System - SAS. User's Guide, version 9, 4.ed., North Caroline, SAS Institute INC., 2002.
TAKEARA P.; TOLEDO, A.L.; GANDRA, E.R.S. et al. Lisina digestível para frangos de corte machos entre 12 e 22 dias de idade. Arq. Bras. Med. Vet. Zootec., v.62, p.1455-1461, 2010.

TOLEDO, A.L.; TAKEARA, P.; BITTENCOURT, L.C. et al. Níveis dietéticos de lisina digestível para frangos de corte machos no período de 1 a 11 dias de idade: desempenho e composição corporal. Rev. Bras. Zootec., v.36, p.1090-1096, 2007.

TRINDADE NETO, M.A.; TOLEDO, A.L.; TAKEARA, P. et al. Dietary levels of lysine for male broilers from 23 to 36 days of age: performance and body composition. Rev. Bras. Zootec., v.40, p.609615, 2011. 